\title{
Effect of Pickling and Activation Treatments on the Performance of Electroless Plating of Ni-B Coating on AZ31 Mg Alloy
}

\author{
Salah Eldin k. A. Abdulhamid ${ }^{1} \quad$ Fatma Kandemirli $^{1} \quad$ Ibrahim M Ghayad $^{2}$ \\ 1. Department of Material Science, Kastamonu University, Turkey \\ 2. Central Metallurgical R\& D Institute, Egypt
}

\begin{abstract}
Pickling is particularly critical before Ni-B electroless plating to create a uniform and catalytically active surface. In the present work, pickling treatment of AZ31 Mg alloy was performed in phosphoric acid followed by immersion in $40 \% \mathrm{HF}$. The effect of concentration of both $\mathrm{H}_{3} \mathrm{PO}_{4}$ and $\mathrm{HF}$ as well as the effect of time were investigated. The pickled samples were then electroless plated with a Ni-B composite. The performance of the Ni-B composite coating was investigated under the SEM.Results show that the highest quality coating was obtained upon pickling AZ31 Mg alloy samples in 50\% phosphoric acid for $1 \mathrm{~min}$, followed by activation in $40 \% \mathrm{HF}$ for $15 \mathrm{~min}$. Higher concentration of $\mathrm{H}_{3} \mathrm{PO}_{4}$ results in a higher concentration of $\mathrm{PO}_{3}^{-4}$, leading to a higher tendency to produce insoluble films (mainly $\mathrm{Mg}_{3}\left(\mathrm{PO}_{4}\right)_{2}$ and $\mathrm{AlPO}_{4}$ ) on the substrate surface slowing down the rate of $\mathrm{Mg}$ alloy oxidization and dissolution. Activation of pickled AZ31 Mg samples in HF results in the formation of corrosion resistant dense layer of magnesium fluoride. SEM investigation predicted the electroless deposition of an adherent compact layer of $\mathrm{Ni}-\mathrm{B}$ composite coating on the $\mathrm{H}_{3} \mathrm{PO}_{4} / \mathrm{HF}$ pickled AZ31 samples.
\end{abstract}

Key Words: AZ31 Mg alloy, pickling, activation, HF, electroless plating

DOI: $10.7176 / \mathrm{CMR} / 11-5-04$

Publication date:May $31^{\text {st }} 2019$

\section{Introduction}

Magnesium and its alloys have wide applications in different industries, including aircraft, motor vehicle as well as metallurgical, chemical and electrical industries. $\mathrm{Mg}$ has a density of $1.74 \mathrm{~g} / \mathrm{cm}^{3}$ which is $35 \%$ lighter than aluminum $\left(2.7 \mathrm{~g} / \mathrm{cm}^{3}\right)$ and over four times lighter than steel $\left(7.86 \mathrm{~g} / \mathrm{cm}^{3}\right)$. Mg-Al alloy is the most common category of magnesium alloys. Aluminum has a strong passivation tendency in presence of oxygen and results in the precipitation of $\beta$ phase, which is highly cathodic with respect to the matrix $[1,2]$. AZ31B is a wrought magnesium alloy having good strength, ductility, corrosion resistance and weldability. AZ31B are widely applied in aircraft fuselages, cell phone and laptop cases, speaker cones and concrete tools. AZ31B can be super formed at elevated temperatures to produce a wide variety of intricate components for automotive uses [3].

Magnesium and its alloys are prone to galvanic corrosion when coupled internally with impurities or second phases or by external coupling with dissimilar metals. The oxide film formed on its surface is of poor quality and tend to dissolve in water or breakdown chemically in many environments, namely; chloride, bromide, sulfate, nitrate, and chromate [4].

Pretreatment of $\mathrm{Mg}$ alloys and particularly AZ31 Mg alloy is a key factor in obtaining a good electroless plating layer. Successful pretreatment before Ni-B electroless plating results in creating a uniform and catalytically active surface. There are mainly two types of preferred pretreatments for $\mathrm{Mg}$ alloy, including zinc immersion and direct electroless nickel plating (ENP). The direct ENP is simpler and more convenient. Acid pickling in a chromium-containing (VI) solution, followed by activation in a hydrofluoric acid solution is usually employed in the conventional pretreatment processes of direct ENP [5]. Several chromium-free pickling and activation processes were investigated by Xie et al [6] in order to develop an eco-friendly pretreatment for electroless Ni-P plating on magnesium alloy. The coatings obtained from pickling in $\mathrm{H}_{3} \mathrm{PO}_{4}$ solution followed by $\mathrm{NH}_{4} \mathrm{HF}_{2}$ activation displayed wonderful properties in both adhesion and corrosion resistance. Shao et al [7] investigated the effect of three acid pickling and activation solutions on the electroless Ni-P plating on $\mathrm{AZ91} \mathrm{Mg}$ alloy. After pickling in $\mathrm{HNO}_{3} 25 \mathrm{ml} / 1, \mathrm{H}_{3} \mathrm{PO}_{4} 25 \mathrm{ml} / 1$ and activation in $\mathrm{NH}_{4} \mathrm{H}_{2} \mathrm{PO}_{4} 80-100 \mathrm{~g} / \mathrm{L}, \mathrm{NH}_{4} \mathrm{~F} 30-50 \mathrm{~g} / \mathrm{L}$ at room temperature, AZ91 could be directly electroless plated. The structure of Ni-P coating was uniform, amorphous highly resistant towards corrosion. Wang et al [8] deposited Ni-B coating directly on acetic acid pickled AZ91D. The electroless Ni-B plating exhibits a uniform surface and an amorphous structure with a high corrosion resistance.

The present work investigates the effect of pretreatment of AZ31 Mg alloy in phosphoric acid and hydrofluoric acid on the nickel-boron electroless plating of the alloy.

\section{Materials and Method}

The experimental work was preceded as follows:

- $\mathrm{AZ31} \mathrm{Mg}$ alloy with the composition (wt\%) of $\mathrm{Al} 2.5 \sim 3.0, \mathrm{Zn} 0.7 \sim 1.3, \mathrm{Mn}>0.2$, and $\mathrm{Mg}$ balance was 
cut into about $20 \mathrm{~mm} \times 20 \mathrm{~mm} \times 2.0 \mathrm{~mm}$ square shape coupons and used as the substrate for the experiment. The specimens were polished with $\mathrm{SiC}$ waterproof abrasive papers of 400 and 1200 grit and then washed in distilled water, and finally dried in air.

- Substrates were immersed in alkaline media (a mixture of $50 \mathrm{~g} / 1 \mathrm{NaOH}$ and $10 \mathrm{~g} / 1 \mathrm{Na}_{3} \mathrm{PO}_{4}$ ) for $10 \mathrm{~min}$ so that dust, grease etc. were removed from the surface of magnesium.

- The pretreatment process was performed in two steps:

o Pickling treatment: samples were pickled in phosphoric acid solution where the effect of acid concentration and pickling time were thoroughly investigated.

o Activation treatment: Pickled samples were activated in hydrofluoric acid where the effect of acid concentration and activation time were also investigated

The pretreated samples were mounted in the Ni-B electrless plating bath and kept at fixed temperature for reasonable time. The bath composition and operation conditions are shown in Table (1). The path was prepared using analytical grade reagents and double distilled water.

Table (1): Bath Composition and Deposition Conditions

\begin{tabular}{|c|c|}
\hline Bath composition & Concentration , g/l \\
\hline Sodium borohydride $\left(\mathrm{NaBH}_{4}\right)$ & 8 \\
Nickel chloride $\left(\mathrm{NiCl}_{2}\right)$ & 10 \\
Ethylenediamine & 90 \\
Sodium hydroxide & 90 \\
Lead nitrate or Stannous Chloride & 0.0145 \\
\hline Conditions: Temperature $=65-95^{\circ} \mathrm{C}$; Deposition time $=1-4 \mathrm{~h}$ \\
\hline
\end{tabular}

The surface and cross section morphologies of the coated sample was observed with field emission scanning electron microscopy (FESEM).

\section{Results and Discussions}

Visual inspection of $\mathrm{Ni}-\mathrm{B}$ electroless plated samples was carried out to investigate the effect of pretreatment conditions on the performance of coated samples. The coated samples were designated non coated, poor, good and very good according to the surface coverage and uniformity of the coating. Results are shown in Figure 1 and Tables 2-4. It is shown that no coating was obtained after pickling in phosphoric acid at low concentrations $(5,10$, and $20 \%)$. Coating starts to prevail at $30 \%$ phosphoric acid concentration; however, the formed coating was poorly adhered and poorly covered the sample surface. Increasing phosphoric acid concentration up to $40 \%$ improves the coating quality to a marked extent. Upon increasing the acid concentration up to $50 \%$, an excellent coating regarding the adherence and coverage was obtained. Further increase in the acid concentration up to $60 \%$ deteriorates the coating quality.

Following pickling, AZ31 Mg alloy samples were activated in hydrofluoric (HF) acid at various concentrations. Table 2 shows the effect of HF concentration on the coating quality. It is shown that no coating was obtained at low HF concentrations $(10 \%)$ while poor coating was obtained upon increasing the HF concentration up to $10 \%$. Further increase in the HF concentration results in a marked improvement in the coating quality whereas the highest quality coating obtained at the highest HF concentration of $40 \%$.

The effect of pickling and activation time on the coating quality is presented in Table 4 . It is shown that the optimum pickling time was $1 \mathrm{~min}$. and the coating quality was deteriorated with the increase in pickling time. On the other hand the optimum activation time was $15 \mathrm{~min}$. below and above which the coating quality deteriorates.

The aforementioned results indicate that the highest quality coating was obtained upon pickling alloy AZ31 $\mathrm{Mg}$ in 50\% phosphoric acid for $1 \mathrm{~min}$, followed by activation in $40 \% \mathrm{HF}$ for $15 \mathrm{~min}$. 


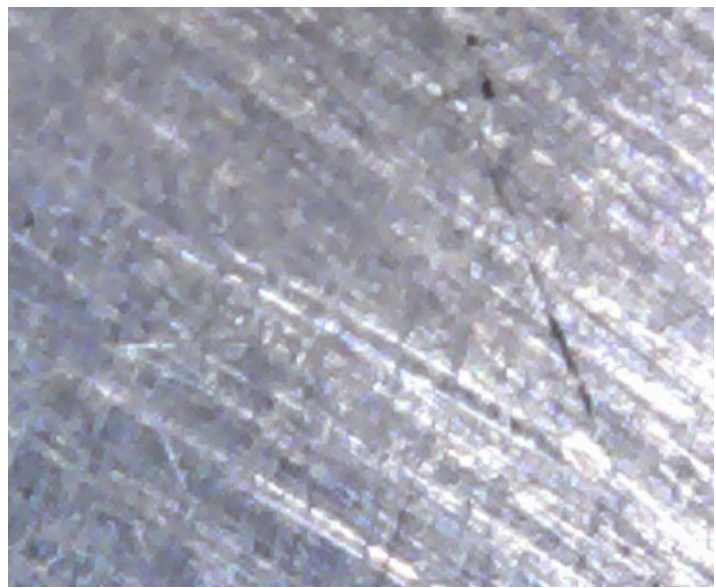

As polished sample (non coated)

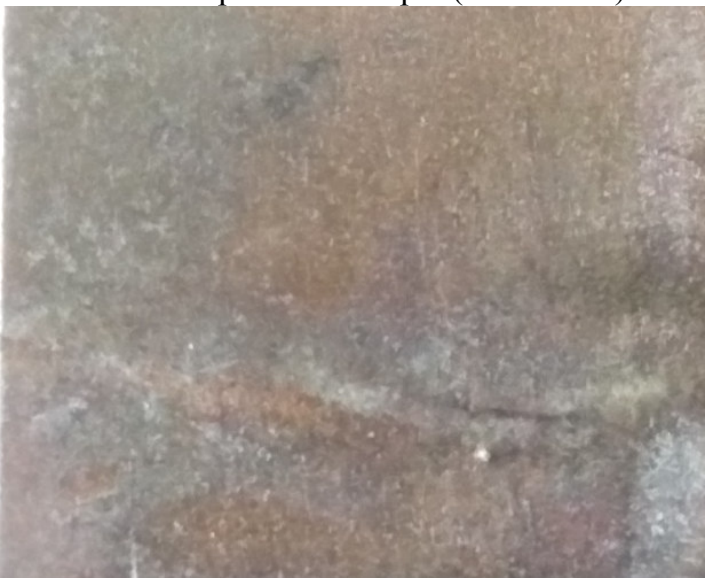

Good Coating

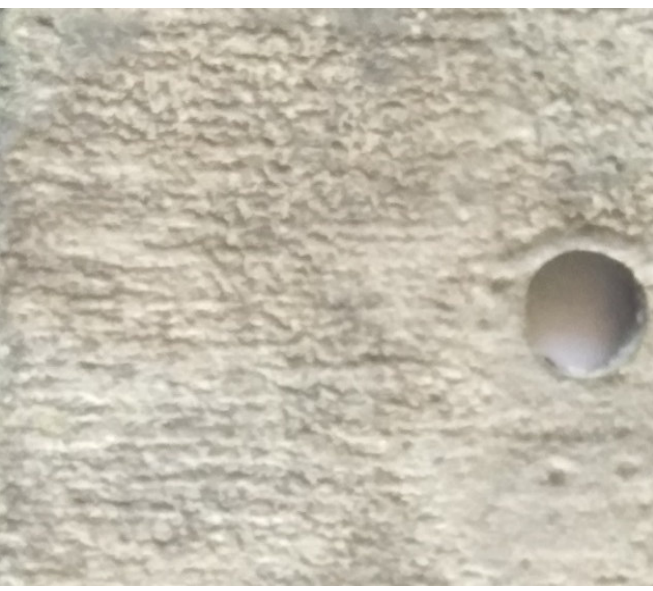

Poor coating

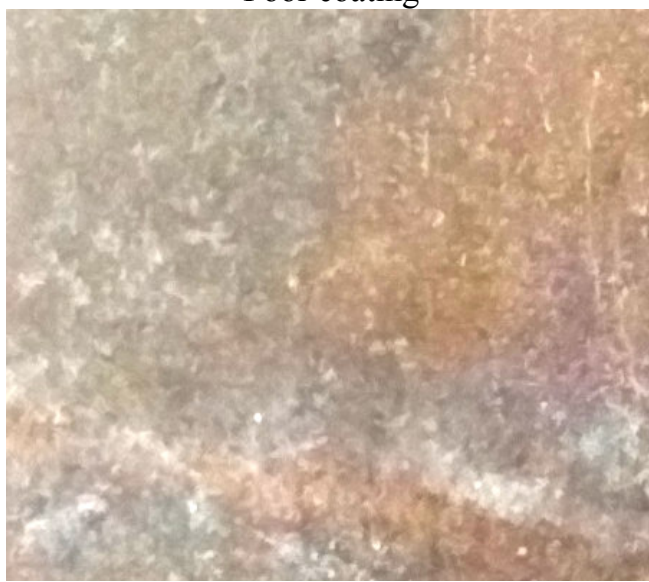

Excellent Coating

Figure 1: Optical photographs of coated samples

Table 2: Effect of phosphoric acid pickling pretreatment on the Ni-B coating quality.

$O$ Denotes no coating formed, $\triangle$ Denotes the formation of poor quality coating,

$\diamond$ Denotes the formation of good coating, $\nabla$ Denotes the formation of excellent coating

\begin{tabular}{|c|c|}
\hline Vol.\% $\mathbf{H}_{3} \mathbf{P O}_{4}$ & Coating quality \\
\hline 5 & $\bigcirc$ \\
\hline 10 & 0 \\
\hline 20 & $\bigcirc$ \\
\hline 30 & $\diamond$ \\
\hline 40 & $\diamond$ \\
\hline 50 & $\diamond$ \\
\hline 60 & $\diamond$ \\
\hline
\end{tabular}

Table 3: Effect of hydrofluoric acid activation on the Ni-B coating quality

\begin{tabular}{|c|c|}
\hline Vol.\% HF & Coating Quality \\
\hline 10 & $\bigcirc$ \\
\hline 20 & $\triangle$ \\
\hline 30 & $\diamond$ \\
\hline 40 & $\varnothing$ \\
\hline
\end{tabular}


Table 4: Effect of phosphoric acid pickling pretreatment time and hydrofluoric acid activation time on the $\mathrm{Ni}-\mathrm{B}$ coating quality

\begin{tabular}{|c|c|c|c|}
\hline Pickling time / min. & Coating quality & Activation time/ min & Coating quality \\
\hline 1 & $\diamond$ & 8 & $\Delta$ \\
\hline 2 & $\diamond$ & 10 & $\diamond$ \\
\hline 5 & $\triangle$ & 15 & $\diamond$ \\
\hline & & 20 & $\triangle$ \\
\hline
\end{tabular}

Increasing the acid concentration results in the increase in the number of hydrogen ions (decreased $\mathrm{pH}$ ) as well as the dissolution rate of the alloy. However, further increase in $\mathrm{H}_{3} \mathrm{PO}_{4}$ concentration above $50 \%$ results in a higher concentration of $\mathrm{PO}_{3}^{-4}$, leading to a higher tendency to produce insoluble films (mainly $\mathrm{Mg}_{3}\left(\mathrm{PO}_{4}\right)_{2}$ and $\mathrm{AlPO}_{4}$ on the substrate surface slowing down the rate of $\mathrm{Mg}$ alloy oxidization and dissolution. The corrosion mechanism of AZ31 Mg alloy in the etching solution probably includes the following reactions [9-10]:

$$
\begin{aligned}
& \mathrm{Mg} \longrightarrow \mathrm{Mg}^{2+}+2 \mathrm{e}^{-} \\
& \mathrm{Al} \mathrm{H}^{+}+2 \mathrm{e}^{-} \longrightarrow \mathrm{Al}^{3+}+3 \mathrm{e}^{-}
\end{aligned}
$$

Meanwhile, the oxidized $\mathrm{Mg}$ and $\mathrm{Al}$ ions combined with $\mathrm{PO}_{4}{ }^{3-}$ :

$$
\begin{array}{lll}
3 \mathrm{Mg}^{2+}+\mathrm{PO}_{4}{ }^{3-} \longrightarrow \mathrm{Al}^{3+} & \longrightarrow \mathrm{PO}_{4}{ }^{3-} \longrightarrow \mathrm{Mg}_{3}\left(\mathrm{PO}_{4}\right)_{2} & {[4]} \\
\mathrm{AlPO}_{4} & {[5]}
\end{array}
$$

Upon increasing $\mathrm{H}_{3} \mathrm{PO}_{4}$ concentration up to $50 \%$, enlarge etch pits are mostly formed on the alloy surface. These enlarge pits tend to coalesce. The formation of such pits result in the detachment of some parts of substrate matrix with insoluble phosphate precipitation. Consequently, the etching protection by phosphate films weakened gradually with increasing concentration of $\mathrm{H}_{3} \mathrm{PO}_{4}$ up to $50 \%$ with the formation of a rough and rugged surface after pickling.

After pickling in $50 \% \quad \mathrm{H}_{3} \mathrm{PO}_{4}$ for $1 \mathrm{~min}$, coarse surfaces were obtained. This microstructure (Figure 2) on the substrate surface provides more chemical active sites for the electroless Ni-B plating and provides also surface pits for mechanically interlocking resulting in improving coating adhesion [11-12]. The pickled surface must have some chemical activity for $\mathrm{Ni}$ ions where metallic $\mathrm{Mg}$ could be exposed in some areas and react with $\mathrm{Ni}$ ions in the electroless plating bath.
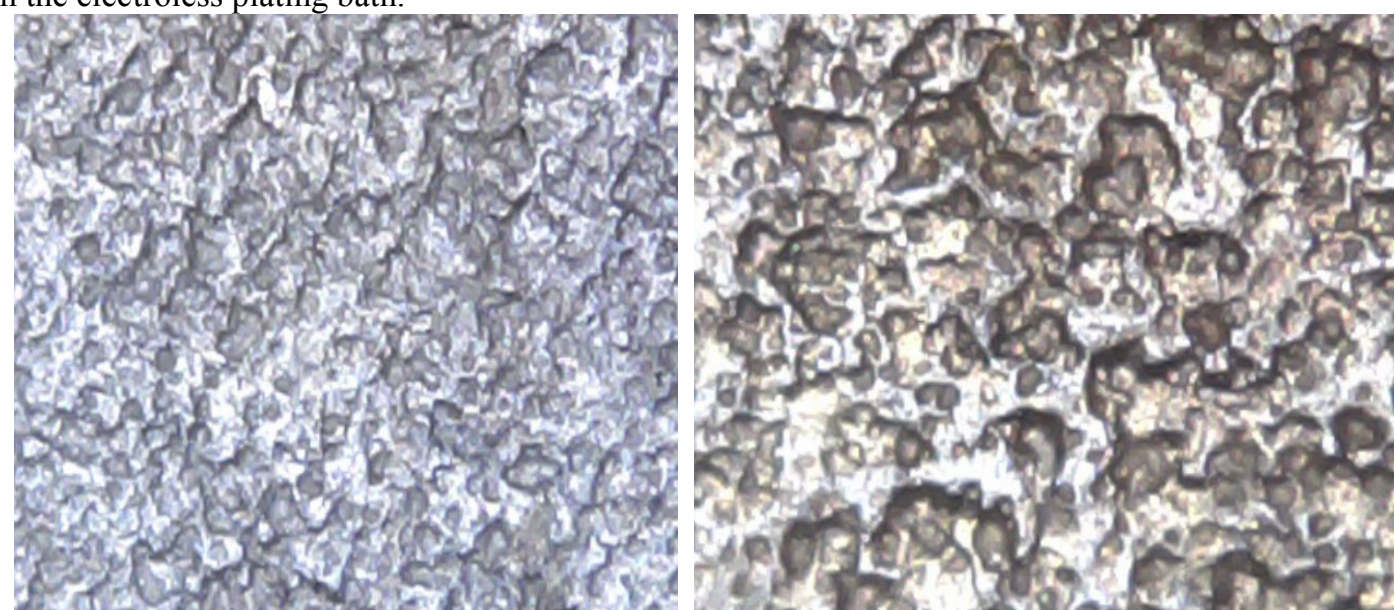

Figure 2: Optical microscopic photograph of $\mathrm{Mg}$ alloy after pickling in $\mathrm{H}_{3} \mathrm{PO}_{4}$ solution $(\mathrm{X}=\mathbf{5 0 0})$

The immersion of $\mathrm{Mg}$ alloy AZ31 in HF solutions resulted in a gas evolution at the starting period of the treatment. The gas emission is related to hydrogen formed by the reaction of $\mathrm{HF}$ with $\mathrm{Mg}$, according to the following equation [13]:

$$
2 \mathrm{HF}+\mathrm{Mg} \rightarrow \mathrm{MgF}_{2}+\mathrm{H}_{2}
$$

It was reported that the reaction of AZ31 with HF is much slower than that of pure magnesium ingots. This leads to the suggestion that the alloying elements $\mathrm{Al}, \mathrm{Zn}$ and $\mathrm{Mn}$ improve the chemical stability of magnesium compounds in acidic fluoride environments. In the early beginning of activation in HF, a slight decrease of the magnesium concentration could be observed after the HF treatment, due to metal dissolution. This magnesium dissolution resulted in an enrichment of some elements, like $\mathrm{Al}$ and $\mathrm{Mn}$. In addition, the treatment of alloy samples in HF probably dissolve the iron impurities in the alloy and hence reduced the $\mathrm{Fe} / \mathrm{Mn}$ ratio to a value below the critical value $(0.032)$ showing that this treatment is a cleaning process with respect to iron. On the other hand, copper and nickel, the most deleterious impurities for magnesium alloys, have a low solid solubility 
in magnesium probably due to their presence in more stable phases, that is what provides active cathodic sites that enhance magnesium oxidation.

The surface of the substrate treated by HF showed relatively smooth morphology (Figure 3 ) decreasing the contact area with corrosion medium, consequently leading to higher corrosion resistance for the $\mathrm{Mg}-\mathrm{HF}$ surface. In addition, the dense microstructure of magnesium fluoride (Figure 3) may also contribute to the enhanced corrosion resistance. On the other side, it is well known that the fluoride element generally exhibits hydrophobicity. The magnesium fluoride layer can not only resist the substrate from the corrosion medium but also provide a hydrophobic surface to prevent the corrosion ions from penetrating into the magnesium substrate, leading to the enhanced corrosion resistance [14].

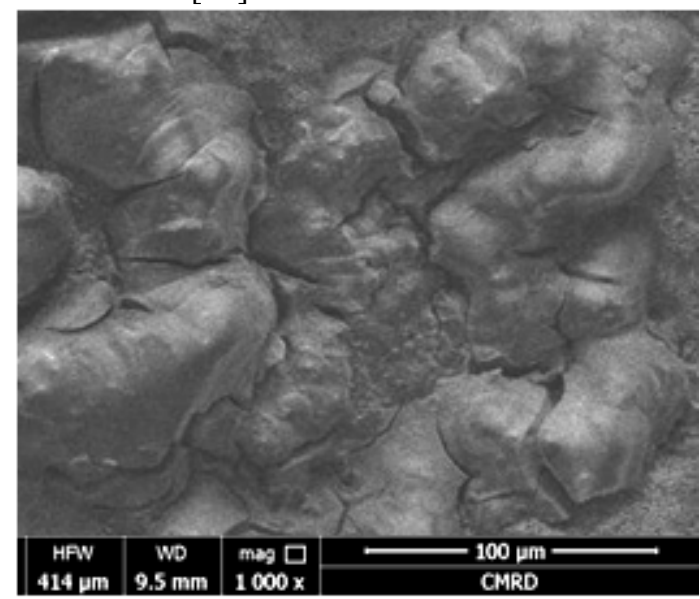

Figure 3: SEM image of AZ31 Mg alloy after pickling for $1 \mathrm{~min}$. in

$50 \% \mathrm{H} 3 \mathrm{PO} 4$ followed by activation in $40 \% \mathrm{HF}$ for $15 \mathrm{~min}$

Electroless plating of AZ31 Mg alloy was performed in the plating bath mentioned in Table (1). The electroless plating conditions were determined previously by the authors [15]. Figure 4 represents the cross section of the Ni-B coating formed in the presence of $8 \mathrm{~g} / \mathrm{L} \mathrm{NaBH}_{4}$. The average coating thickness is $4.85 \mu \mathrm{m}$.

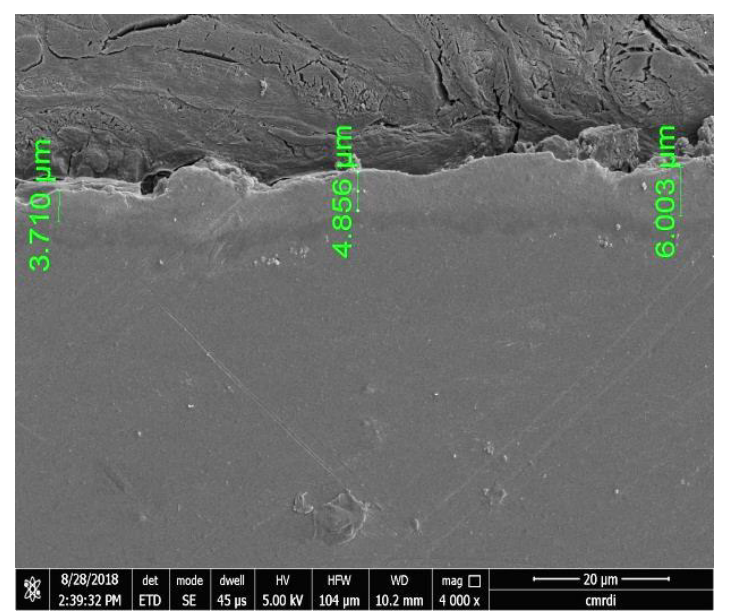

Figure 4: Cross section of Ni-B electroless coating on AZ31 Mg alloy in the presence of $8 \mathrm{~g} / \mathrm{L} \mathrm{NaBH}_{4}$ at $85^{\circ} \mathrm{C}$ and $1 \mathrm{~h}$

In the initial deposition stage, the substrate surface possesses a large number of active sites for rapid $\mathrm{Ni}$ replacement of $\mathrm{Mg}$ and nucleation reactions, forming small nickel nuclei from edge to center in the surface film pores. Boron atoms may also be adsorbed to the Ni surface, and promote the formation of new nuclei. Meanwhile, the corrosion of the substrate results in the deposition of $\mathrm{Ni}_{2} \mathrm{~B}$. After the substrate surface is completely covered by $\mathrm{Ni} / \mathrm{Ni}-\mathrm{B}$, the freshly deposited nodular nickel acts as a catalyst for continuous $\mathrm{Ni}$ deposition reaction and the main electroless plating process becomes from Ni replacement to Ni deposition. Together with slow deposition of $\mathrm{Ni}_{2} \mathrm{~B}$, deposited nickel particles are built up layer by layer to form a smooth and dense Ni-B coating [16-18].

\section{Conclusions}

1. The present work postulates that the highest quality coating was obtained upon pickling the $\mathrm{AZ} 31 \mathrm{Mg}$ alloy in 50\% phosphoric acid for $1 \mathrm{~min}$, followed by activation in $40 \% \mathrm{HF}$ for $15 \mathrm{~min}$. Pickling 
treatment provides more chemical active sites for the electroless Ni-B plating and provides also surface pits for mechanically interlocking resulting in improving coating adhesion.

2. Activation of pickled sample in $40 \% \mathrm{HF}$ for $15 \mathrm{~min}$. results in the development of smooth morphology and dense coating layer. This layer decreases the contact area with corrosion medium leading to higher corrosion resistance for the Mg-HF surface.

3. The electroless nickel coating exhibits a uniform surface with an average thickness of $4.85 \mu \mathrm{m}$.

\section{References}

1. M.K. Kulekci, Magnesium and its alloys applications in automotive industry, Int J Adv Manuf Technol, 39 (2008)851-865.

2. C. Ying-liang, Q. Ting-wei, W. Hui-min, Z. Zhao, Comparison of corrosion behaviors of AZ31, AZ91,AM60 and ZK60 magnesium alloys, Transactions of nonferrous metals society of china, 19(2009)517-524.

3. S. Housh and B Mikucki, Selection and Application of Magnesium and Magnesium Alloys, Properties and Selection: Non Ferrous Alloys and Special Purpose Materials, Vol 2, ASM Hand Book, ASM International, 1990, p 455-479.

4. R.K. Singh Raman, R.K.,'The Role of Microstructure in Localized Corrosion of Magnesium Alloys", Metallurgical and Materials Transactions A, 35A (2004) 2525-2531.

5. X. Shui , Y. Wang, J. Peng, P. Yan, B. Yan, X. Fang, Y. Xu, Recent Progress in Electroless Ni Coatings for Magnesium Alloys, Int. J. Electrochem. Sci., 10 (2015) 1261 - 1273

6. Zhi-Hui Xie, Fang Chen, Shu-Rong Xiang, Jun-Li Zhou, Zheng-Wei Song, Gang Yu, Studies of Several Pickling and Activation Processes for Electroless Ni-P Plating on AZ31 Magnesium Alloy, Journal of The Electrochemical Society, 162 (3) D115-D123 (2015).

7. Z. Shao, Z. Cai, R. Hu, S. Wei, The study of electroless nickel plating directly on magnesium alloy, Surf. Coat. Technol., 249 (2014) 42-47.

8. Z.C. Wang, F. Jia, L. Yu, Z.B. Qi, Y. Tang, G.L. Song, Direct electroless nickel-boron plating on AZ91D magnesium alloy, Surf. Coat. Technol., 206 (2012) 3676-3685.

9. Z.C. Wang, F. Jia , L. Yu, Z.B. Qi, Y. Tang, G.-L. Song, Direct electroless nickel-boron plating on AZ91D magnesium alloy, Surf Coat Techn, 206 (2012) 3676-3685.

10. ZHX. F. Chen, SR X., JL Zhou, ZW Song, G. Yu, Studies of Several Pickling and Activation Processes for Electroless Ni-P Plating on AZ31 Magnesium Alloy, Journal of The Electrochemical Society, 162 (3) D115-D123 (2015)

11. J E Gray, B Luan. Protective coatings on magnesium and its alloys-a critical review, J. Alloys Compd. 336, 88 (2002).

12. C. Gu, J. Lian, G. Li, L. Niu, and Z. Jiang, Electroless Ni-P plating on AZ91D magnesium alloy from a sulfate solution, J. Alloys Compd. 391, 104 (2005).

13. T.F. da Conceicao, N. Scharnagl, C. Blawert, W. Dietzel, K.U. Kainer, Thin Surface modification of magnesium alloy AZ31 by hydrofluoric acid treatment and its effect on the corrosion behaviour Solid Films 518 (2010) 5209-5218

14. Chang-Jiang Pan, Li-Qun Pang, Yu Hou, Yue-Bin Lin, Tao Gong, Tao Liu, Wei Ye, Hong-Yan Ding, Improving Corrosion Resistance and Biocompatibility of Magnesium Alloy by Sodium Hydroxide and Hydrofluoric Acid Treatments, Appl. Sci. 2017, 7, 33; doi:10.3390/app7010033

15. Salah Eldin k. A. Abdulhamid, Ibrahim M Ghayad, Fatma Kandemirli, Electroless Plating of Ni-B Composite Coating on AZ31 Mg alloy, Chemistry and Materials Research, 10 (7) (2018) 11-19.

16. C. Gu, J. Lian, G. Li, L. Niu, and Z. Jiang, Electroless Ni-P plating on AZ91D magnesium alloy from a sulfate solution, J. Alloys Compd. 391, 104 (2005).

17. Q.L. Rao, B. Gang, Q.H. Lu, H.W. Wang, X. Fan, Microstructure evolution of electroless Ni-B film during its depositing process, Appl. Surf. Sci. 240 (2005) 28.

18. Y.L. Lo, B.J. Hwang, Decomposition of sodium borohydride in an electroless nickel bath, Ind. Eng. Chem. Res. 33 (1994) 56. 